\title{
Lung Function, Respiratory Muscle Strength, and Thoracoabdominal Mobility in Women With Fibromyalgia Syndrome
}

\author{
Meire Forti MSc, Antonio R Zamunér PhD, Carolina P Andrade, and Ester Silva PhD
}

\begin{abstract}
BACKGROUND: Fibromyalgia syndrome (FMS) is associated with a variety of symptoms, such as fatigue and dyspnea, which may be related to changes in the respiratory system. The objective of this work was to evaluate pulmonary function, respiratory muscle strength, and thoracoabdominal mobility in women with FMS and its association with clinical manifestations. METHODS: The study included 23 women with FMS and 23 healthy women (control group). Pulmonary function, respiratory muscle strength, and thoracoabdominal mobility were assessed in all participants. Clinical manifestations such as number of active tender points, pain, fatigue, well-being, and general pressure pain threshold and pressure pain threshold in regions involved in respiratory function were also assessed. For data analysis, the Mann-Whitney test and Spearman correlation coefficient were used. RESULTS: The FMS group showed lower values of maximum voluntary ventilation $(P=.030)$, maximal inspiratory pressure $(P=.003)$, and cirtometry at the axillary and xiphoid levels $(P<.001$ and $P<.001$, respectively $)$ as well as higher cirtometry at the abdominal level $(P=.005)$ compared with the control group. However, there was no significant difference between groups for maximum expiratory pressure. In predicted percentage, maximal inspiratory pressure showed significant positive correlation with axillary cirtometry $(r=0.41$, $P=.049)$ and negative correlation with the number of active tender points $(r=-0.44$, $P=.031)$ and fatigue $(r=-0.41, P=.049)$. CONCLUSIONS: Subjects with FMS had lower respiratory muscle endurance, inspiratory muscle strength, and thoracic mobility than healthy subjects. In addition, inspiratory muscle strength was associated with the number of active tender points, fatigue, and axillary mobility. Key words: fibromyalgia; respiratory muscle strength; lung function; respiratory function tests; respiratory mechanics; respiratory muscles. [Respir Care 2016;61(10):1384-1390. () 2016 Daedalus Enterprises]
\end{abstract}

\section{Introduction}

Fibromyalgia syndrome (FMS) is a rheumatic condition of increasing prevalence worldwide, ${ }^{1}$ characterized by dif-

\footnotetext{
The authors are affiliated with the Department of Physical Therapy, Federal University of São Carlos, São Carlos, São Paulo, Brazil.

This study was supported by São Paulo Research Foundation (FAPESP) Grants 2013/16008-0 and 2011/22122-5 and by National Council for Scientific and Technological Development (CNPq) Grants 483032/2012-3 and 307187/2013-6. The authors have disclosed no conflicts of interest.

Correspondence: Meire Forti MSc, Department of Physical Therapy, Federal University of São Carlos, Rodovia Washington Luís, Km 235, 13565-905, São Carlos, SP, Brazil. E-mail: me.fisio@hotmail.com.
}

DOI: $10.4187 /$ respcare.04401 fuse chronic pain of non-inflammatory origin and hypersensitivity in specific anatomical sites, called tender points. ${ }^{2}$ Although pain in FMS is widespread, the most affected regions are related to respiratory mechanics, such as the upper trapezius muscle, the suboccipital muscles, the anterior cervical region, and the second rib. ${ }^{3}$ The literature reports that diseases that promote pain and stiffness of thorax and spine muscles can decrease the functional capacity of muscles involved in breathing, facilitating the development of respiratory disorders. ${ }^{4}$

Thus, the presence of pain in regions related to respiratory mechanics and the presence of symptoms, such as dyspnea and fatigue, have drawn attention to the respiratory evaluation in women with FMS..$^{5-10}$ However, the results are still incipient, and some of them are contradictory. Kesiktas et al ${ }^{10}$ reported an obstructive respiratory pattern in women with FMS, due to the lower values of 
$\mathrm{FEV}_{1}$ and $\mathrm{FEV}_{1} / \mathrm{FVC}$. On the other hand, other studies ${ }^{7-9}$ have found no abnormalities in the lung function of women with FMS.

Regarding respiratory muscle strength and thoracic mobility, Ozgocmen et $\mathrm{al}^{7}$ found reduced values in subjects with FMS compared with healthy subjects. However, Sahin et $\mathrm{al}^{8}$ observed impairment only in respiratory muscle strength, with no change in thoracic mobility. The causes of these changes are still unknown, but some hypotheses have been proposed. Ozgocmen et $\mathrm{al}^{7}$ suggested that respiratory muscle weakness in subjects with FMS can be explained by the low thoracic mobility and that painful reflex inhibition, caused by the fear of pain, might be one of the major factors explaining this relationship. Conversely, some studies ${ }^{8,10}$ have proposed that the low respiratory muscle strength and thoracic mobility are due to respiratory muscle dysfunction that stems from low levels of physical activity in this population. However, despite the hypotheses raised by previous studies, whether the respiratory dysfunction is related to clinical manifestations, such as number of tender points, fatigue, and pain, still remains to be clarified. In addition, to our knowledge, no studies have assessed pressure pain threshold in specific regions involved in respiratory function or abdominal mobility in FMS.

Based on the above, it was hypothesized that subjects with FMS have lower respiratory muscle strength and lower thoracoabdominal mobility, despite normal lung function. In addition, these changes are expected to be associated with clinical symptoms, such as pain, fatigue, and low pressure pain threshold, in regions related to respiratory function. Thus, the present study aimed to evaluate lung function, respiratory muscle strength, and thoracoabdominal mobility as well as to evaluate the relationship between these variables and the clinical symptoms presented by women with FMS.

\section{Methods}

\section{Study Design and Participants}

A cross-sectional case-control study was carried out between December 2013 and August 2014 at the Federal University of São Carlos. One hundred twenty potential volunteers with clinical diagnosis of primary FMS (the FMS group), according to criteria from the American College of Rheumatology, ${ }^{2}$ were screened, and 23 eligible subjects participated in the study. Twenty-three healthy women matched to the FMS group for age, body mass index, and level of physical activity ${ }^{11}$ composed the healthy control group. Participants were recruited through announcements made in the university physical therapy and rheumatologic and orthopedic clinics, social media, and personal invitation.

\section{QUICK LOOK}

\section{Current knowledge}

Fibromyalgia syndrome (FMS) is a rheumatic condition characterized by widespread chronic pain. Nevertheless, the most affected regions are related to respiratory mechanics. Respiratory muscle strength is reduced in subjects with FMS compared with healthy subjects, although the causes of these changes are still unknown. Results regarding pulmonary function and thoracic mobility are controversial.

\section{What this paper contributes to our knowledge}

Subjects with FMS had lower respiratory muscle endurance, inspiratory muscle strength, and thoracic mobility than healthy subjects. Inspiratory muscle strength was associated with the number of active tender points, fatigue, and axillary mobility.

Exclusion criteria were smoking, history of systemic diseases such as diabetes mellitus, hypertension or any respiratory, cardiac or neurological disease, difficulties in understanding the experimental procedures, obesity (body mass index, BMI $>40 \mathrm{~kg} / \mathrm{m}^{2}$ ), regular practice of physical activity, according to the International Physical Activity Questionnaire (IPAQ) ${ }^{11}$, or use of drugs that could influence the variables studied (i.e. bronchodilators, analgesics, tranquilizers or antidepressants). All participants read and signed an informed consent form approved by the Institution Ethics Committee for Research on Human Subjects (protocol 112.508).

\section{Experimental Procedures}

All measurements were carried out in the morning ( $8 \mathrm{AM}$ to $12 \mathrm{PM}$ ) by the same evaluator. Room temperature was maintained at $22^{\circ} \mathrm{C}$, and relative air humidity was maintained at $40-60 \%$.

All participants attended the laboratory 3 times, separated by an interval of at least one week. The first visit consisted of anamnesis and clinical and physical examinations. In the second visit, participants underwent exercise testing, supervised by a cardiologist. The hemodynamic variables evaluated during this test showed behavior as expected, and no evidence of electrocardiographic changes was found. On the same day, participants were acquainted with the research protocol and were instructed to abstain from stimulants (eg, coffee, tea, soft drinks) and alcoholic beverages for $24 \mathrm{~h}$ before examination and to have a light meal at least $2 \mathrm{~h}$ before the test. To avoid any residual fatigue, subjects were asked to refrain from stren- 
uous physical activity at least 2 days before the tests. The third visit was devoted to clinical manifestations, lung function, respiratory muscle strength, and thoracoabdominal mobility assessments. Upon arrival at the laboratory, participants were asked about their health status and whether they had complied with the experimental instructions.

Pressure Pain Threshold and Tender Points. Pressure pain threshold was determined at 18 tender points described by Wolfe et $\mathrm{al}^{2}$ using a digital algometer (OE-220: Tissue Hardness Meter \& Algometer, Ito Co, Tokyo, Japan) according to the methodology described by Chesterton et al. ${ }^{12}$ The general pressure pain threshold was considered as the average of all points assessed. ${ }^{2}$ To determine the pressure pain threshold at the regions most involved in respiratory function, the average at the following points, bilaterally, was considered: (1) intertransverse spaces between C5 and C7 (sternocleidomastoid muscle); (2) midpoint of the top edge of the upper trapezius muscle belly at the midpoint of the upper border; (3) second costochondral joint. Tender points were counted when the pressure pain threshold reported was a pressure of $<4 \mathrm{~kg} .{ }^{2,13}$

Pain, Fatigue, and Well-Being. Current levels of general pain, fatigue, and well-being were assessed using a $100-\mathrm{mm}$ visual analog scale. Participants recorded pain intensity, fatigue, and well-being by drawing a vertical line on the respective horizontally positioned visual analog scale. The left end of the visual analog scale $(0 \mathrm{~mm})$ represented no pain, no fatigue, and the worst well-being condition, respectively. The right end $(100 \mathrm{~mm})$ represented the most severe pain imaginable, most severe fatigue imaginable, and best well-being condition, respectively. No intermediate divisions or descriptive terms were present in the scale.

Fibromyalgia Impact Questionnaire. Participants with FMS answered the Fibromyalgia Impact Questionnaire to determine the impact of fibromyalgia on their quality of life. The higher the score, the greater the impact of FMS on subjects' quality of life. ${ }^{14}$ This questionnaire was used to better characterize the FMS group (Table 1).

Pulmonary Function Testing. Spirometry tests were performed using a flow module (ULTIMA PFX, Medical Graphics, St. Paul, Minnesota). Technical procedures and acceptability and reproducibility criteria were performed according to the American Thoracic Society standards. ${ }^{15}$ All subjects remained seated, used a nose clip during the course of the maneuvers, and completed at least 3 acceptable maneuvers. The following variables were recorded: slow vital capacity (SVC), FVC, $\mathrm{FEV}_{1}$, and maximum voluntary ventilation (MVV). Absolute values were com-
Table 1. Age, Body Mass Index, and Cardiorespiratory Baseline Characteristics and Clinical Manifestations of the Fibromyalgia Syndrome Group and Control Group

\begin{tabular}{|c|c|c|c|}
\hline $\begin{array}{l}\text { Characteristics/Clinical } \\
\text { Manifestations }\end{array}$ & $\begin{array}{c}\text { FMS } \\
\text { Group } \\
(n=23)\end{array}$ & $\begin{array}{c}\text { Control } \\
\text { Group } \\
(n=23)\end{array}$ & $P$ \\
\hline \multicolumn{4}{|l|}{ Basic data } \\
\hline Age, y & $48.7 \pm 7.4$ & $49.3 \pm 7.0$ & .80 \\
\hline BMI, $\mathrm{kg} / \mathrm{m}^{2}$ & $27.6 \pm 2.9$ & $26.4 \pm 4.6$ & .31 \\
\hline Respiration, breaths/min & $14.7 \pm 4.0$ & $15.0 \pm 2.2$ & .82 \\
\hline Heart rate, beats/min & $70.5 \pm 7.5$ & $73.0 \pm 7.9$ & .28 \\
\hline $\mathrm{SBP}, \mathrm{mm} \mathrm{Hg}$ & $115.6 \pm 11.9$ & $109.1 \pm 9.9$ & .051 \\
\hline $\mathrm{DBP}, \mathrm{mm} \mathrm{Hg}$ & $67.6 \pm 5.1$ & $69 . \pm 8.2$ & .34 \\
\hline \multicolumn{4}{|l|}{ Clinical manifestations } \\
\hline Number of active tender points & $17.3 \pm 1.3$ & $10.5 \pm 6.1$ & .001 \\
\hline PPT-G, $\mathrm{kg} / \mathrm{cm}^{2}$ & $2.0 \pm 0.5$ & $4.1 \pm 1.6$ & $<.001$ \\
\hline PPT-R, $\mathrm{kg} / \mathrm{cm}^{2}$ & $1.4 \pm 0.4$ & $2.9 \pm 1.3$ & $<.001$ \\
\hline Visual analogue scale pain, $\mathrm{mm}$ & $54 \pm 23$ & $08 \pm 18$ & $<.001$ \\
\hline Visual analogue scale fatigue, $\mathrm{mm}$ & $45 \pm 23$ & $12 \pm 21$ & $<.001$ \\
\hline Visual analogue scale well-being, $\mathrm{mm}$ & $61 \pm 24$ & $85 \pm 20$ & .001 \\
\hline Disease duration, $\mathrm{y}$ & $8.0 \pm 4.7$ & NA & NA \\
\hline FIQ, total score & $68.0 \pm 14.0$ & NA & NA \\
\hline \multicolumn{4}{|l|}{$\overline{\text { Values are mean } \pm \text { SD. }}$} \\
\hline \multicolumn{4}{|l|}{ FMS = fibromyalgia syndrome } \\
\hline \multicolumn{4}{|l|}{$\mathrm{BMI}=$ body mass index } \\
\hline \multicolumn{4}{|l|}{$\mathrm{SBP}=$ systolic blood pressure } \\
\hline \multicolumn{4}{|l|}{$\mathrm{DBP}=$ diastolic blood pressure } \\
\hline \multicolumn{4}{|l|}{ PPT-G $=$ pressure pain threshold - general } \\
\hline \multirow{2}{*}{\multicolumn{4}{|c|}{$\mathrm{PPT}-\mathrm{R}=$ pressure pain threshold in most regions involved in respiratory function }} \\
\hline $\mathrm{NA}=$ not applicable & & & \\
\hline FIQ = Fibromyalgia Impact Questionnaire & & & \\
\hline
\end{tabular}

pared with those predicted by Pereira ${ }^{16}$ for Brazilian adult populations.

Respiratory Muscle Strength. Respiratory muscle strength was assessed by measuring the maximal respiratory pressure using a digital manometer MVD300 (Globalmed, Porto Alegre, Brazil) connected to a microcomputer (MVD300 software, Globalmed). Maximal inspiratory pressure $\left(\mathrm{P}_{\text {Imax }}\right)$ was performed from residual volume, whereas maximal expiratory pressure was assessed from the total lung capacity. All measurements were performed with the participant seated and using a 2-mm aperture mouthpiece ${ }^{17}$ and a nose clip to prevent air leakage. Five maximal inspiratory and expiratory effort maneuvers were performed without perioral air leakage, sustained for at least $2 \mathrm{~s}$, with values close to each other $(\leq 10 \%)$. The measurement with the greatest value was used for analysis. ${ }^{17,18}$ Once the measurement had been obtained, the percent-of-predicted $\mathrm{P}_{\operatorname{Imax}}$ and maximal expiratory pressure values were calculated according to the prediction equation proposed by Neder et al. ${ }^{18}$

Thoracoabdominal Mobility. To assess the thoracoabdominal mobility, cirtometry was performed at the axillary, xiphoid, and abdominal levels, using a measuring tape. For the axillary, xiphoid, and abdominal levels, land- 
marks were the anterior axillary line, the tip of the xiphoid process, and the navel, respectively. Measurements were performed with participants in the standing position with hands on hips and chest half-naked. Thoracoabdominal expansion was obtained from the difference between measurements of maximal expiration followed by maximal inspiration. ${ }^{19,20}$ Measurements were performed 3 times at each level, with the highest value being used for the study. For each level evaluated, participants were asked to perform maximal expiration (until residual volume), followed by maximal inspiration (until total lung capacity). The differences between inspiratory and the expiratory measurements for each of the 3 levels were considered as the thoracoabdominal mobility indices. ${ }^{19,20}$

Statistical Analysis. Sample size calculation was based on the study by Ozgocmen et $\mathrm{al}^{7}$ using the GPower 3.1 software (Heinrich-Heine-Universität, Düsseldorf, Germany). To detect a difference of $15 \mathrm{~cm} \mathrm{H}_{2} \mathrm{O}$ for $\mathrm{P}_{\text {Imax }}$, with significance level $\alpha=0.05$ and power of $80 \%$, a sample size of 19 participants in each group was suggested. Statistical procedures were performed using BioEstat 5.0 (Instituto Mamirauá, Belém, Pará, Brazil) and Statistica 6.1 for Windows (StatSoft, Tulsa, Oklahoma) software. The Shapiro-Wilk test was used to verify the normality of data. For comparisons between groups, the MannWhitney test was used. The relationships between respiratory variables and the number of active tender points, pain, fatigue, and pressure pain threshold were verified using the Spearman correlation coefficient. Correlation coefficients were classified as weak correlation $(\mathrm{r}=0-0.30)$, moderate correlation $(\mathrm{r}=0.31-0.70)$, and strong correlation $(r>0.70)$, according to criteria proposed by Dancey and Reidy. ${ }^{21}$ The level of significance was set at $5 \%$.

\section{Results}

Data regarding age, body mass index, resting cardiorespiratory variables, and clinical manifestations are shown in Table 1. There was no significant difference between groups for age, body mass index, and cardiorespiratory variables. However, as expected, the FMS group showed higher visual analog scale pain $(P<.001)$, visual analog scale fatigue $(P<.001)$, number of active tender points $(P=.001)$, lower general pressure pain threshold $(P<.001)$, lower pressure pain threshold in regions most involved in respiratory function $(P<.001)$, and visual analog scale well-being $(P=.001)$ compared with the control group.

Table 2 shows the results referring to lung function, respiratory muscle strength, and thoracoabdominal mobility measurements. Regarding lung function, the FMS group showed lower absolute SVC $(P=.003), \mathrm{FVC}(P=.003)$, and $\operatorname{FEV}_{1}$ values $(P=.01)$ as well as lower MVV, ex-
Table 2. Respiratory Variables of the Fibromyalgia Syndrome Group and Control Group

\begin{tabular}{|c|c|c|c|}
\hline Variables & $\begin{array}{l}\text { FMS Group } \\
\quad(n=23)\end{array}$ & $\begin{array}{l}\text { Control Group } \\
\quad(n=23)\end{array}$ & $P$ \\
\hline \multicolumn{4}{|l|}{ Lung function } \\
\hline SVC, L & $3.0 \pm 0.6$ & $3.5 \pm 0.5$ & .003 \\
\hline SVC, $\%$ predicted $*$ & $91.3 \pm 16.2$ & $96.5 \pm 9.3$ & .20 \\
\hline $\mathrm{FVC}, \mathrm{L} / \mathrm{s}$ & $3.1 \pm 0.6$ & $3.7 \pm 0.5$ & .003 \\
\hline FVC, $\%$ predicted* & $92.3 \pm 17.3$ & $100.6 \pm 8.2$ & .052 \\
\hline $\mathrm{FEV}_{1}, \mathrm{~L} / \mathrm{s}$ & $2.5 \pm 0.5$ & $2.8 \pm 0.3$ & .01 \\
\hline $\mathrm{FEV}_{1}, \%$ predicted $*$ & $95.3 \pm 19.3$ & $98.9 \pm 9.6$ & .43 \\
\hline $\mathrm{MVV}, \mathrm{L} / \mathrm{min}$ & $91.2 \pm 18.6$ & $107.9 \pm 14.7$ & .001 \\
\hline MVV, \% predicted* & $96.5 \pm 19.2$ & $108.1 \pm 14.6$ & .030 \\
\hline \multicolumn{4}{|l|}{ Respiratory muscle strength } \\
\hline $\mathrm{P}_{\text {Imax }}$ obtained $\left(\mathrm{cm} \mathrm{H}_{2} \mathrm{O}\right)$ & $65.1 \pm 17.0$ & $82.7 \pm 19.8$ & .002 \\
\hline $\mathrm{P}_{\text {Imax }}, \%$ predicted $\dagger$ & $76.0 \pm 19.7$ & $96.6 \pm 22.2$ & .001 \\
\hline $\mathrm{P}_{\text {Emax }}$ obtained, $\mathrm{cm} \mathrm{H}_{2} \mathrm{O}$ & $92.7 \pm 20.6$ & $102.3 \pm 18.9$ & .10 \\
\hline $\mathrm{P}_{\text {Emax }}, \%$ predicted $\dagger$ & $109.7 \pm 26.1$ & $120.3 \pm 21.6$ & .14 \\
\hline \multicolumn{4}{|l|}{ Thoracoabdominal mobility } \\
\hline $\mathrm{CA}, \mathrm{cm}$ & $4.3 \pm 0.7$ & $6.1 \pm 1.2$ & $<.001$ \\
\hline $\mathrm{CX}, \mathrm{cm}$ & $4.1 \pm 1.2$ & $5.6 \pm 1.1$ & $<.001$ \\
\hline $\mathrm{CAb}, \mathrm{cm}$ & $3.1 \pm 1.5$ & $2.0 \pm 0.9$ & .005 \\
\hline \multicolumn{4}{|c|}{$\begin{array}{l}\text { Values are mean } \pm \text { SD. } \\
\text { * Values expressed as a percentage of the predicted value according to the prediction equation } \\
\text { proposed by Pereira et al.16 } \\
\text { † Values expressed as a percentage of the predicted value according to the prediction equation } \\
\text { proposed by Neder et al. } 18 \\
\text { FMS = fibromyalgia syndrome } \\
\text { SVC = slow vital capacity } \\
\text { MVV = maximal voluntary ventilation } \\
\mathrm{P}_{\text {Imax }}=\text { maximal inspiratory pressure } \\
\mathrm{P}_{\text {Emax }}=\text { maximal expiratory pressure } \\
C A=\text { axillary cirtometry } \\
C X=\text { cirtometry xifoidiana } \\
\mathrm{CAb}=\text { abdominal cirtometry }\end{array}$} \\
\hline
\end{tabular}

pressed as absolute and percent-of-predicted values ( $P=.001$ and $P=.030$, respectively), compared with the control group. However, there was no significant difference between groups for SVC $(P=.20), \operatorname{FVC}(P=.052)$, and $\operatorname{FEV}_{1}(P=.43)$ expressed as percent of predicted.

Regarding respiratory muscle strength, the FMS group showed lower absolute and percent-of-predicted $\mathrm{P}_{\mathrm{Imax}}$ values compared with the control group $(P=.002$ and $P=.001$, respectively). There was no significant difference between groups for absolute and percent-of-predicted maximal expiratory pressure values $(P=.10$ and $P=.14$, respectively).

Concerning the thoracoabdominal mobility, the FMS group showed lower axillary cirtometry $(P<.001)$ and xiphoid cirtometry values $(P<.001)$ compared with the control group. However, abdominal cirtometry was higher in the FMS group $(P=.005$; Table 2$)$.

Positive correlations were found between $\mathrm{P}_{\text {Imax }}$ values in percent of predicted and axillary cirtometry $\left(\mathrm{r}_{\mathrm{s}}=0.41\right.$, $P=.049)$. In addition, negative correlations were observed between $\mathrm{P}_{\text {Imax }}$ percent of predicted and the number 
ficient intensity to promote stress and beneficial adaptations to the respiratory system.

To elucidate possible mechanisms associated with reduced muscle strength in women with FMS, the association between $\mathrm{P}_{\text {Imax }}$ (percent of predicted), clinical symptoms, and thoracoabdominal mobility was evaluated. Our findings showed that the weaker the inspiratory muscle strength, the greater the number of active tender points, the greater the fatigue, and the lower the thoracic mobility at the axillary level.

One possible explanation for the association between number of active tender points and inspiratory muscle strength may stem from the findings of Klaver-Król et al. ${ }^{26}$ The authors reported that subjects with FMS present higher conduction velocity of the fiber muscle membrane, which is associated with greater number of tender points. The increased conduction velocity in the muscle membrane can be attributed to abnormalities in the muscle oxidative metabolism in Type 1 muscle fibers (moth-eaten fibers and ragged-red fibers) and hypotrophy of Type 2 muscle fibers. ${ }^{27,28}$ Thus, these changes may also have occurred in the respiratory muscles, which would explain the association observed in this study. In addition, the number of active tender points has a functional character and provides complementary information to the self-reported pain. ${ }^{26,29}$ Therefore, our results support the hypothesis that not only the fear of pain but also the pain itself may be associated with decreased muscle strength.

Another factor that may have influenced the low muscle strength values in FMS participants is the axillary mobility. In a study by Lanza et al, ${ }^{30}$ the authors found through linear regression analysis that axillary cirtometry was the variable that best explained changes in $\mathrm{P}_{\text {Imax }}$, agreeing with the findings of the present study. Indeed, studies have shown that the $\mathrm{P}_{\text {Imax }}$ performed from residual volume (maximal exhalation), which requires a higher thoracic expansibility, is more effective than the $\mathrm{P}_{\text {Imax }}$ performed from functional residual capacity. The authors infer that the technique performed from residual volume results in additional increase in pulmonary and rib cage elastic recoil forces, enhancing the performance and the maximal inspiratory pressure. ${ }^{31}$ Therefore, the reduced inspiratory muscle strength in the FMS group may be related to the lower axillary mobility.

Fatigue is another factor that must be considered to explain the low muscle strength values. A previous study ${ }^{32}$ showed that subjective symptoms, such as fatigue, might influence functional ability and physical performance. Thus, not only pain but also fatigue may have limited performance in the execution of maneuvers at maximal respiratory pressures. However, the analysis used in this study did not allow inferring causality. Thus, the reduction in inspiratory muscle strength as a possible causal factor of fatigue cannot be ruled out and should be evaluated in future studies to elucidate whether the improvement in respiratory muscle strength and thoracoabdominal mobility promote improvement in fatigue and other clinical symptoms.

Another interesting finding of this study was the results for thoracoabdominal mobility. To our knowledge, this was the first study to assess mobility at the axillary, xiphoid, and abdominal levels in subjects with FMS. Previous studies have assessed thoracic mobility only on the basis of the cirtometric measurement in the region corresponding to the fourth intercostal space. ${ }^{7,8}$

Corroborating the results of previous studies, the present findings revealed reduced thoracic mobility. However, surprisingly, women with FMS had higher abdominal mobility. Some studies have shown that, although pain in FMS is diffuse, the muscles related to the respiratory mechanics are the most compromised. ${ }^{3}$ It is suggested that the pain in respiratory muscles may have restrained the chest expansion, resulting in greater abdominal mobility during maximum breathing required for the performance of cirtometry in order to compensate for the reduced thoracic mobility.

Based on the above, our results have important clinical implications encouraging a wider approach in the evaluation and treatment of patients with FMS. Therefore, not only the musculoskeletal system but also the respiratory system should be of concern for professionals involved in the rehabilitation of these patients. Thus, future studies should propose specific training for respiratory muscles in order to assess the effects on the respiratory system as well as their influence on clinical manifestations in subjects with FMS.

Despite the interesting results of this study, some limitations should be considered. The evaluation of the degree of dyspnea and pressure pain threshold in all muscles involved in breathing (ie, rectus abdominis muscle, scalenes, internal intercostals, etc) could contribute to the interpretation of these results. It was also concluded that correlations were moderate $(r<0.7),{ }^{21}$ and due to the sample size, it was not possible to perform a multiple linear regression analysis to elucidate the association between respiratory variables and clinical symptoms. Another study limitation that should be considered is the use of the International Physical Activity Questionnaire to estimate the physical activity level. Although this questionnaire has been validated and used in several studies, ${ }^{11}$ the use of an accelerometer could allow a more accurate and reliable measure, besides providing some insights regarding the energy expenditure and its association with respiratory dysfunction in FMS. Moreover, the use of optoelectronic plethysmography, which enables the evaluation of the 3-dimensional thoracoabdominal kinematics, may provide important information about respiratory function and me- 


\section{Clinical Manifestations of Fibromyalgia Syndrome}

chanics in patients with FMS and should be addressed in future studies.

\section{Conclusions}

Women with FMS in this study showed lower respiratory muscle endurance, inspiratory muscle strength, and thoracic mobility. Furthermore, lower inspiratory muscle strength was associated with lower axillary mobility as well as a higher number of active tender points and increased fatigue.

\section{REFERENCES}

1. Queiroz LP. Worldwide epidemiology of fibromyalgia. Curr Pain Headache Rep 2013;17(8):356.

2. Wolfe F, Smythe HA, Yunus MB, Bennett RM, Bombardier C, Goldenberg DL, et al. The American College of Rheumatology 1990 criteria for the classification of fibromyalgia: report of the Multicenter Criteria Committee. Arthritis Rheum 1990;33(2):160-172.

3. Maquet D, Croisier JL, Demoulin C, Crielaard JM. Pressure pain thresholds of tender point sites in patients with fibromyalgia and in healthy controls. Eur J Pain 2004;8(2):111-117.

4. Casas A, Pavía J, Maldonado D. Respiratory muscle disorders in chest wall diseases. Arch Bronconeumol 2003;39(8):361-366.

5. Weiss DJ, Kreck T, Albert RK. Dyspnea resulting from fibromyalgia. Chest 1998;113(1):246-249.

6. Çetin A, Sivri A. Respiratory function and dyspnea in fibromyalgia syndrome. J Musculoskeletal Pain 2001;9(1):7-15. doi: 10.1300/ J094v09n01_02.

7. Ozgocmen S, Cimen OB, Ardicoglu O. Relationship between chest expansion and respiratory muscle strength in patients with primary fibromyalgia. Clin Rheumatol 2002;21(1):19-22.

8. Sahin G, Ulubaş B, Calikoğlu M, Bolgen Cime OB, Erdoğan C. Is chest expansion a determinant of pulmonary muscle strength in primary fibromyalgia? Joint Bone Spine 2004;71(2):140-143.

9. Sener U, Ucok K, Ulasli AM, Genc A, Karabacak H, Coban NF, et al. Evaluation of health-related physical fitness parameters and association analysis with depression, anxiety, and quality of life in patients with fibromyalgia. Int J Rheum Dis 2013 [Epub ahead of print] doi: 10.1111/1756-185X.12237.

10. Kesiktas N, Karagülle Z, Erdogan N, Yazıcıoglu K, Yılmaz H, Paker $\mathrm{N}$. The efficacy of balneotherapy and physical modalities on the pulmonar system of patients with fibromyalgia. J Back Musculoskelet Rehabil 2011;24(1):57-65.

11. Craig CL, Marshall AL, Sjöström M, Bauman AE, Booth ML, Ainsworth BE, et al. International Physical Activity Questionnaire: 12country reliability and validity. Med Sci Sports Exerc 2003;35(8): 1381-1395.

12. Chesterton LS, Sim J, Wright CC, Foster NE. Interrater reliability of algometry in measuring pressure pain thresholds in healthy humans, using multiple raters. Clin J Pain 2007;23(9):760-766.

13. Latorre PA, Santos MA, Heredia-Jiménez JM, Delgado-Fernández M, Soto VM, Mañas A, et al. Effect of a 24-week physical training programme (in water and on land) on pain, functional capacity, body composition and quality of life in women with fibromyalgia. Clin Exp Rheumatol 2013;31(6 Suppl 79):S72-S80.
14. Marques AP, Santos AMB, Assumpção A, Matsutani LA, Lage LV, Pereira CAB. Validation of the Brazilian version of the Fibromyalgia Impacto Questionnaire (FIQ). Rev Bras Reumatol 2006;46(1):24-31. doi: 10.1590/S0482-50042006000100006 .

15. American Thoracic Society. Standardization of spirometry 1994 update. Am J Respir Crit Care Med 1995;152(3):1107-1136.

16. Pereira CAC. Espirometria. J Pneumol 2002;28(Suppl 3):S1-S82.

17. Black FL, Hyatt RE. Maximal respiratory pressures: normal values and relationship to age and sex. Am Rev Respir Dis 1969;99(5):696702 .

18. Neder JA, Andreoni S, Lerario MC, Nery LE. Reference values for lung function tests: II. maximal respiratory pressures and voluntary ventilation. Braz J Med Biol Res 1999;32(6):719-727.

19. Paulin E, Brunetto AF, Carvalho CRF. Effects of a physical exercises program designed to increase thoracic mobility in patients with chronic obstructive pulmonary disease. J Pneumol 2003;29(5):287294. doi: 10.1590/S0102-35862003000500007.

20. Moreno MA, Catai AM, Teodori RM, Borges BLA, Cesar MC, Silva E. Effect of a muscle stretching program using the Global Postural Reeducation method on respiratory muscle strength and thoracoabdominal mobility of sedentary young males. J Bras Pneumol 2007; 33(6):679-689.

21. Dancey C, Reidy J. Statistics without maths for psychology: using SPSS for Windows. London: Prentice Hall, 2004;Chapter 6, 1682011.

22. Moreno MA, Catai AM, Teodori RM, Borges BLA, Zuttin RS, Silva E. Respiratory system adaptations relative to pulmonary function in response to a muscle stretching program using the Global Posture Reeducation method. Fisioter Pesqui 2009;16(1):11-15. doi: 10.1590/ S1809-29502009000100003.

23. Laghi F, Tobin MJ. Disorders of the respiratory muscles. Am J Respir Crit Care Med 2003;168(1):10-48.

24. Bogdanis GC. Effects of physical activity and inactivity on muscle fatigue. Front Physiol 2012;3:142.

25. Caidahl K, Lurie M, Bake B, Johansson G, Wetterqvist H. Dyspnoea in chronic primary fibromyalgia. J Intern Med 1989;226(4):265-270.

26. Klaver-Król EG, Zwarts MJ, Klooster PM, Rasker JJ. Abnormal muscle membrane function in fibromyalgia patients and its relationship to the number of tender points. Clin Exp Rheumatol 2012; 30(74):S44-S50.

27. Bengtsson A. The muscle in fibromyalgia. Rheumatology 2002;41(7): 721-724.

28. Gerdle B, Ostlund N, Grönlund C, Roeleveld K, Karlsson JS. Firing rate and conduction velocity of single motor units in the trapezius muscle in fibromyalgia patients and healthy controls. J Electromyogr Kinesiol 2008;18(5):707-716.

29. Jacobs JW, Rasker JJ, van der Heide A, Boersma JW, de Blécourt AC, Griep EN, et al. Lack of correlation between the mean tender point score and self-reported pain in fibromyalgia. Arthritis Care Res 1996;9(2):105-111.

30. Lanza FC, de Camargo AA, Archija LRF, Selman JPR, Malaguti C, Dal Corso S. Chest wall mobility is related to respiratory muscle strength and lung volumes in healthy subjects. Respir Care 2013; 58(12):2107-2112

31. Windisch W, Hennings E, Sorichter S, Hamm H, Criée CP. Peak or plateau maximal inspiratory mouth pressure: which is best? Eur Respir J 2004;23(5):708-713.

32. White KP, Speechley M, Harth M, Ostbye T. Comparing self-reported function and work disability in 100 community cases of fibromyalgia syndrome versus controls in London, Canada. Arthritis Rheum 1999;42(1):76-83. 